\title{
Modeling using IS Methodologies: Some Guidelines based on Authenticity and Contemporary Epistemology
}

\author{
Stephen K. Probert \\ Cranfield University, United Kingdom
}

\author{
S.k.probert@rmcs.crantield.ac.uk
}

\begin{abstract}
This paper focuses on two contemporary problems in IS development: those of choosing which IS methodology to use (if any), and the practical problems related to using an IS methodology whilst intervening in modern, complex, turbulent organizations. As IS practitioners must, increasingly, intervene in such organizations, it is argued that an important issue for IS research is whether they choose to do so in (what will be characterized as) an authentic manner. The epistemological consequences of authentic intervention are then explored, and it is concluded that many approaches to IS development are authentically possible and practical, although softer approaches have always emphasized the human dimension of IS development. Although the terms 'relevance' and 'rigor' are used herein they are not used in quite the same sense as they are used in the IS research debate concerning relevance and rigor.
\end{abstract}

Keywords: method, epistemology, authenticity

\section{Introduction}

As Loucopoulos and Karakostas argue, "Information systems are entering a new phase, moving beyond the traditional automation of routine organizational processes and towards the assisting of critical tactical and strategic enterprise processes. Development of such systems needs to concentrate on organizational aspects, delivering systems that are closer to the culture of organizations and the wishes of individuals." (Loucopoulos and Karakostas, 1995, p. 4). Clearly, such demands are difficult to achieve in practice. Over the past twenty years or so there has been a considerable growth of interest in IS development methodologies. Also, unsurprisingly, (given the above remarks) there has been a steady growth in interest in softer methodological approaches - more attuned to the social needs of the organization than the technical aspects of IS development. One result of the growth of interest in (and use of) methodologies has led to a new set of problems for IS practitioners; two of which will be considered herein. Let

Material published as part of this proceedings, either on-line or in print, is copyrighted by the author with permission granted to the publisher of Informing Science for this printing. Permission to make digital or paper copy of part or all of these works for personal or classroom use is granted without fee provided that the copies are not made or distributed for profit or commercial advantage AND that copies 1) bear this notice in full and 2) give the full citation on the first page. It is permissible to abstract these works so long as credit is given. To copy in all other cases or to republish or to post on a server or to redistribute to lists requires specific permission from the author. us call the first problem the problem of (IS) methodological rigor. Simply stated, this problem concerns the degree to which a IS practitioner needs to adhere to the prescriptions of the chosen methodology, i.e. should he/she use a cookbook or a toolkit approach. Academically, it is worth qualifying this problem somewhat, as different methodologies - indeed different versions of the same methodology have tended to give different prescriptions in (precisely) this respect. Fidler and Rogerson neatly capture this notion with the phrase, "The rule prescriptiveness of the methodology" (Fidler and Rogerson, 1996, p. 269). It will be argued below that, regardless of the rule prescriptiveness of the methodology, the extent to which an IS practitioner follows the precise prescriptions of a (highly rule-

prescriptive) methodology remains a matter of choice for the IS practitioner. Furthermore, there is considerable evidence to support the view that such choices are frequently made, e.g. as Jayaratna concludes:

"The structure, steps, models, values and philosophy of the methodology-in-action may very well be different from either those explicitly outlined in the methodology (creators' rationale) or those that were interpreted and changed by the methodology users in the context of their own 'mental constructs' (methodology users' rationale) before intervention. This is because a methodology has to match the dynamic nature of the situation and the interactions of 


\section{Modeling using IS Methodologies}

the methodology users in the situation." (Jayaratna, 1994, p. 229)

As the practical choice as to whether to use a methodology in a cookbook or a toolkit manner remains largely open, this paper will focus on this issue. The second problem concerns that of methodology choice and the movement between methodologies (within the same project). Let us call the second problem the problem of methodology relevance. A considerable literature has built-up in recent years to help practitioners with this problem (e.g. Jayaratna, 1994), and this paper will not revisit this territory. However, what will be argued is that the problem of methodological rigor and the problem of methodology relevance are epistemologically related; they are "two sides of the same coin". Consequently, whilst the main focus of this paper concerns the problem of methodological rigor, many of the conclusions may help to inform the debate on the problem of methodology relevance. The paper utilizes two broad areas of philosophy to develop its interpretative framework, i.e. (what might be termed) antifoundational ethics (authenticity) and (what would generally be termed) contemporary epistemology. It should be noted that both of these broad areas of philosophy will not be discussed in detail "in themselves", but the requisite concepts and arguments will be introduced where appropriate. By keeping the philosophical discussion to a minimum it is hoped that relevance can be emphasized without a serious loss of philosophical rigor.

\section{Personal Authenticity and Ethical Codes}

Firstly, to characterize the concept of authenticity, a brief explanation will be given. Given that there is a lack of $a b$ solute guidance as to how one is to act in any given situation, the question of "what should one do...?" raises severe difficulties. Some sorts of authenticity questions may be familiar to the readers of this paper. As a consultant, the author experienced several authenticity problems, a few are given as example questions here:

1. Should I use a methodology that has embedded values that I do not agree with?

2. Should I use a methodology, which, in my judgment, is wholly inappropriate to the circumstances pertaining in the organization?
3. Should I attempt to improve organizational performance by introducing greater accountability in a lowwage organization?

These are difficult ethical questions, and whilst some of these may be (ostensibly) covered by the codes of conduct and practice of professional IS bodies, others may not be (see Walsham, 1996). Also, such decisions require degrees of interpretation, and therefore judgments about such matters are likely to vary from person to person. In any case, not all IS practitioners are members of professional societies, and not all those members may be aware of the codes of conduct and practice, and no doubt some will choose to ignore such things. More importantly, adherence to any such code is unlikely to be practically enforceable; any adherence would therefore have to be "granted" voluntarily by the IS practitioners concerned:

"In the scientific community the medical specialist has better defined ethical codes than most other groups... They are also enforced by powerful sanctions such as expulsion from the medical profession if serious infringements occur. Many other professionals, including the British Computer Society, have also drawn up ethical codes but these are often vague and difficult to apply and enforce... Ethical responsibilities will also vary both with the nature of work that is being carried out and the nature of the social environment where the work is conducted." (Mumford, 1995, p. 6)

Ultimately, the value of ethical codes per se can be neatly summarized by an 1849 quotation from Thoreau (concerning the value of law itself):

"Must the citizen ever for a moment, or in the least degree, resign his conscience to the legislator? Why has every man a conscience then? I think that we should be men first, and subjects afterward. It is not desirable to cultivate a respect for the law, so much as for the right. The only obligation that I have the right to assume, is to do at any time what I think is right. It is truly enough said, that a corporation has no conscience; but a corporation of conscientious men is a corporation with a conscience. Law never made a man a whit more just; and, by means of their respect for it, even the well disposed are daily made the agents of injustice." (Thoreau, 1995, p. 4)

Because the value of ethical codes are limited, the sorts of questions characterized above (which all IS practitioners must probably face from time to time) may best be understood as questions of personal authenticity, rather than 
being understood as strictly ethical questions. Indeed, it has been suggested that, "[T] he concept of authenticity is a protest against the blind, mechanical acceptance of an externally imposed code of values." (Golomb, 1995, p. 11). Such considerations may be extended to IS methodologies in general, as Jayaratna's (1994) concluding remark indicates:

"We as methodology users must become consciously responsible for our actions. Every intervention in human affairs that does not create tension for us and our clients is either not a serious situation warranting the assistance of methodology ... or it is a situation which will create tension, stress, anxieties and pain in others (victims) instead of in ourselves." (Jayaratna, 1994, p. 236)

The concept of authenticity is often primarily connected to considerations put forward by Nietzsche (1844-1900):

"There is a term Nietzsche himself rarely employs, but which is the most suitable label for a constant object of his philosophical concern - 'authenticity'... Nietzsche's question could now be posed as follows: 'How to live authentically?' ... comfortable acceptance of inherited values, or comfortable evasions of questions of value, will both do the trick. But these are not authentic alternatives..." (Cooper, 1983, p. 2-3)

Nietzsche's concerns about such issues are a constant theme in his texts (especially 1956 and 1974). Cooper elaborates the concept of authenticity via some examples from teaching. He explicates the problems thus:

"A familiar disturbance felt by the teacher arises when some of these [educational] policies, values, or whatever, are not ones to which he can subscribe... The disturbance produces a problem of authenticity, for unless the teacher resigns or is willing to invite considerable friction at work, he must simulate agreement to views that are not his. [Alternatively] ... The thought which may strike the teacher is not that he cannot subscribe to, or authoritatively transmit, various beliefs and values, but that he has slipped into, fallen into, unreflective acceptance of them. They have become part of the school's furniture; they go with the job like the free stationery." (Cooper, 1983, p. 4)

Such questions are intensely personal, and researching how IS practitioners deal (or should deal) with such questions as arise in IS practice will be necessary if real progress is to be made towards the aim of improving IS practice, because slavish adherence to externally imposed codes of conduct is not necessarily a guarantor of ethically proper behavior (it has been argued).

\section{Authenticity and Methodological Precepts}

An example of a tension between methodological adherence and authentic systems development practice can be found within the ubiquitous concept of the systems development life cycle; popularized by Barry Boehm (Boehm, 1976). The consequent life cycle model has been absorbed into nearly every structured IS method propounded ever since; if it is criticized, it is criticized as being a prescription that does not "work" in practice (whatever the precise form of the criticism takes). The usual criticism runs along the lines that the longer one takes to "get the requirements right" the longer it takes to develop a system at all - and the greater the likelihood becomes that the requirements are "out of date":

"The criticisms that are periodically made of the development life cycle concept ... mostly focus on its being a linear, sequential model in which each stage must be completed before the next is begun. This means that it relies heavily on the initial definition of the problem being complete and correct and that the users' requirements will not change in the time taken to progress to final implementation. In the case of modern complex information-systems neither of these assumptions can safely be made..." (Lewis, 1994, p. 75)

Nevertheless the widespread use of life cycle methods for IS developments continues relentlessly (although numerous alternative approaches are often propounded). A recent UK survey was conducted to investigate the use of systems development methods (amongst other things). This survey indicated, "Within systems development, 57\% [of IS practitioners] claim to be using a systems development methodology." (Fitzgerald, et al., 1998). The effect of the widespread adoption of structured methods is to remove personal authenticity from the systems development personnel. Lewis argues:

"The legacies of hard systems thinking, such as the idea of the development life cycle, have become so deeply ingrained in IS thinking that only rarely is note taken of the constraints that they impose upon the way we view the development of information-systems." (Lewis, 1994, p. 75) 


\section{Modeling using IS Methodologies}

Now, as received wisdom becomes a guiding force for decision making, so the possibilities for making any genuine decisions tend to evaporate. As Golomb argues:

"In the context of our everyday humdrum lives, it is hard to know what we genuinely feel and what we really are, since most of our acts are expressions and consequences of conditioning, imitation and convenient conformity."

(Golomb, 1995, pp. 24-25)

Adherence to methodological prescriptions may provide IS practitioners with a convenient set of reasons for not doing what they (truly) feel that they ought to do. The point to stress here is that these motivations (to do what one ought to do on authentic versus methodological grounds) are not identical - they are very different. Indeed, Wastell has pointed out the degree to which the adherence to methodological prescriptions has a value as a social defense mechanism for IS practitioners (Wastell, 1996). Although the main focus of Wastell's paper is to demonstrate how it comes about that methodology gets used as a social defense mechanism he also argues that what is actually needed in systems development situations is quite different:

"[M]any analysts apparently developed a fetishistic dependence on methodology ... They appeared to withdraw from the real job of analysis, of engaging with users in an open and frank debate about system requirements. Instead they withdrew into the womb of security provided by the method. They worried about details of notation, of whether the method was being correctly implemented and of the need to press on and fulfill deadlines rather than ensure that they had really understood what the users wanted." (Wastell, 1996, pp. 35-36)

This can be interpreted as a failure of authenticity on the part of the IS practitioners encountered by Wastell.

\section{Authentic Intervention}

Many models of authenticity have been propounded, but we may consider the Nietzschean approach in isolation. Structured / life cycle methodological precepts make little allowance for the influence of choice on the part of the IS practitioners - who will be (methodologically) guided to investigate practically everything relevant in a particular study. Of course, such detailed and thorough investigations are not only difficult to achieve practically, but run counter to the actual social-psychological conditions in which analysts operate. Firstly, on organizational (social) grounds:
"The modern organizational environment is a far cry from the well-ordered world of the classical bureaucracy, with its elaborate hierarchical division of labor and highly routinized procedures. The modern organization, in contrast, is characterized by constant innovation, by flux and fluidity [which] presents a potent challenge to the social defences that characterize the traditional organization, such as the bureaucratic ritual, which contain anxiety by narrowing attention and by defining rigid roles. The new demands require a broadening of rules, wider boundaries, increased integration and interdependence." (Wastell. 1996, pp. 34-35)

Secondly, can the concept of Nietzschean authenticity help us to understand the psychological demands placed on contemporary IS practitioners? Nietzsche's most important arguments concerning such issues can be found in Book Five of The Gay Science (Nietzsche, 1974). However, his style of writing does not lend itself easily to the discourse of IS development! Golomb makes the following points, concerning how Nietzsche conceptualized the relationship between authenticity and epistemology, in a clear contemporary manner:

“An individual's life comprises a boundless number of experiences and notions, including a tremendous amount of superfluous information. Through awareness of one's authentic needs one may organize and refine this chaos into a harmonious sublimated whole. Initially the self is a bundle of conflicting desires and an array of contradictory possibilities. The self's unity is a function of its own decisions and creations... The search for authenticity is seen as the wish to reflect one's own indeterminacy by spontaneous choice of one of the many possible ways of life. The individual is a kind of artist who freely shapes his self as a work of art." (Golomb, 1995, p. 69)

Prima facie, a great deal of systems development work in a turbulent organizational environment can - indeed must depend on the authenticity of the IS development staff if good systems are to be developed. Slavish adherence to methodological prescriptions can only serve to deny the insights and wisdom attained by IS practitioners (about the actual IS needs of organizations) from many years of experience.

\section{Authenticity, Epistemology and Methodology}

Given that precise methodological guidelines will never be entirely adequate - and may indeed be counterproductive - 
the outstanding problem will be in deciding how to conduct a systems analysis. In contemporary epistemology, an important distinction can be made between our criteria for justification for our belief-sets and prescriptions relating to the conduct of inquiry (for adding to our "stock" of beliefs).

\section{Criteria for justification}

Our criteria for justification will often be based on some notion that what we believe, we believe for "good reasons". A crude (heuristic) example would be the dictum that "seeing is believing". Whilst not adequate in all situations (such as during a Magic show), seeing something ( $\mathrm{x}$ ) occurring generally provides a better justification for believing (that $\mathrm{x}$ occurred) than e.g. hearsay. In contemporary epistemology, seeing is believing would be termed a foundational criterion for justification - as it is based on isolated occurrences, which we would claim to be fairly certain about. We might use some such phrase as "I believe x occurred because I saw it happening." in order to justify our belief that $\mathrm{x}$ occurred. However, another approach to justification is termed coherentism. This approach is holistic, in that it requires that all our beliefs "cohere", i.e. that they do not contradict each other. We might use some such phrase as, "Everything I know about macroeconomics tells me that we have not abolished the business cycle." in order to justify our belief that (e.g.) after a sustained period of economic growth an economic downturn was inevitable. Such a belief would not be justified on any "direct" foundational evidence, but rather by the totality of our beliefs (and previous foundational evidence) pertaining to macroeconomics.

In IS analysis, beliefs are generally justified by foundational arguments, but we can (and, I will argue later, should) use techniques such as cross-referencing between different models (etc.) to check that our beliefs - about how a particular organizational IS functions - are correct. In practice, it is often necessary to obtain further foundational evidence (i.e. "go back to the users") if our belief sets do not cohere. A (somewhat crude) example would be: suppose that Accounts had told us that "No goods are ever ordered unless a Purchase Order had been raised.", whereas Purchasing had told us that "Sometimes goods are obtained without a Purchase Order being raised.". Both beliefs would be foundationally justified - but they are not coherent. Further investigation would be required until we could reach a belief-set that was justified both foundationally and coherently. At any rate, IS methodologies should emphasize a rational, mature approach to the justification of beliefs about an IS:

"The goal of [any rational] inquiry is substantial, significant, illuminating truth; the concept of justification is specifically focused on security, on the likelihood of beliefs being true. Hence my claim that truth-indicative is what criteria of justification need to be to be good... [But] Even if our criteria of justification are truth-indicative, to reach the conclusion that our beliefs are mostly true would require the further assumption that our beliefs are mostly justified. But people have many beliefs in which they are not justified, or are justified to only a very modest degree. Superstition, wishful thinking, self-deception, jumping to conclusions, and so forth, are not, after all, so rare." (Haack, 1993, p. 203)

In a sense, the very point of IS methodologies is to provide adequate, rational, defensible justification for the nature, scope and functioning (etc.) systems that are developed as a result of using an IS methodology. As Jayaratna put it, "Methodologies exist to help us in our reasoning. They attempt to raise our conscious thinking, to make us question the rationale of our planned action and to guide us in the transforming of situations." (Jayaratna, 1994, p. xii). Furthermore, there is a welter of evidence to support the view that correctly understanding the operation of the current system and the users' requirements is crucial to the development of successful information systems. The models developed for the design of a new IS will need to be both (internally) coherent and (foundationally) justified by the users' requirements.

\section{Conduct of inquiry}

Precisely how analysts eventually arrive at such models is a different matter; not less important, but less rigidly definable and more open to variations - such that the varieties of organizational circumstances, in which a particular IS is to be developed, can be adequately catered for. Interestingly, Haack argues that this principle is true for all human inquiry in general:

“... [I]t is doubtful whether it is possible to give rules - as opposed to guidelines, the application of which requires judgment or discretion - for conducting inquiry... the 'conduct of inquiry' project is likely to be more hospitable to pluralism, for there may well be different, equally good, ways of proceeding in inquiry - indeed it may well be that the best thing is for different inquirers to proceed differ- 


\section{Modeling using IS Methodologies}

ently; whereas pluralism with respect to criteria of justification ... is not possible." (Haack, 1993, p. 204)

Consequently, it is no real surprise that both hard and soft IS methodologies have similarities at the level of (how to go about) rational justification - lots of interaction with the users and such like, and no surprise that they have radically different recommendations for the conduct of inquiry - different models with different interpretations as to the purpose of modeling etc. Also, on this basis, new ideas for the conduct of inquiry (i.e. new IS development methodologies) can be cautiously welcomed provided that it can be shown that their criteria for the justification of their (intermediate and final) products adequately meet the criteria proposed (or, rather, endorsed) herein. Interestingly, in this respect there is sufficient common epistemological ground between hard and soft approaches to allow movement between hard and soft approaches, as the organizational circumstances dictate. A systems analyst may choose whichever approach he or she sees fit, and/or consult some texts to decide which methodology to choose in the circumstances pertaining, (e.g. Hirschheim, et al., 1995) without committing themselves to a radically different epistemological basis - at least insofar as rational justification is concerned.

\section{Conduct of inquiry versus criteria of justification}

Haack developed a table to indicate the desirable features of "projects of devising guidelines for the conduct of inquiry" and for "the project of explicating / ratifying criteria of justification". These are summarized below (adapted from Haack, 1993):

\section{"conduct of inquiry"}

More hospitable to pluralism

More recalcitrant to precision

Guidelines, not rules

Require discretion, good epistemic character

Social dimension important

“criteria of justification"

Oriented to truth

Focused on security of belief

Focused on likelihood of belief

Focused on truth-indicativeness of belief
These considerations can help us to evaluate IS methodologies in the following way. For any particular IS methodology, we may simply substitute Haack's conduct of inquiry guidelines, with exception of the requirement (1), which (I would suggest) should be replaced with, "that any particular methodology - and especially a new methodology - should be sufficiently novel and distinct from other methodology with respect to guidelines (2) through (5) to warrant our attention and interest". Moreover, we may ask how any IS methodology meets Haack's criteria of justification; for if it fails to do so then, I conclude, its use should not be advocated. Furthermore, if one examines the conduct of inquiry guidelines one can easily provide a theoretical argument concerning the undesirability of slavishly applying an IS methodology in a "cookbook" manner. Not only should movement between hard and soft methodologies be encouraged by the above analysis, but also "cookbook" uses should be actively discouraged. The appeal of a "cookbook" approach rests on the inability to make an important distinction between how to conduct an inquiry and what the criteria of justification for the products of a IS development project are to be; consequently it violates the freedom a IS practitioner needs to adapt his or her processes of inquiry to the actual needs of the project:

“... [C]oncerns about justification are focused on one dimension, specifically, of the goal of inquiry ... This is not to suggest that the two kinds of epistemological project here distinguished are unrelated ... It is only to insist that, though related, they are distinct. But it is the distinctness of the two projects that needs emphasis here, because they have frequently been run together." (Haack, 1993, pp. 203204)

In IS development methodologies (and, in particular, in their "theoretical underpinnings"), the consequences of "running these projects together" will result in a failure to discern the real differences between using a methodology in "toolkit" mode and in "cookbook" mode. A cookbook approach, similar to that described in Wastell (1996), will not result in improved justification for the models developed. A toolkit approach is not epistemically sloppy; rather it can now be seen as being (generally) epistemically desirable. Methodologies such as Soft Systems Methodology (Checkland and Scholes, 1990; Checkland and Holwell, 1998) have always recognized as much. Of course, there will be appropriate cases where a near-cookbook approach to methodology-use can sensibly be advocated. An inexperienced practitioner, with little or no opportunity to call on the resources of more experienced IS practitioners, may well do better with a cookbook approach - rather than no 
methodological approach at all. Moreover, there will always be phases / stages / tasks in a project where a near cookbook approach is the only practical approach available But, generally speaking, the practical significance of methodological prescriptions should determine which aspects of a methodology - even of near-cookbook process within a methodology - are actually performed.

\section{Conclusion}

This paper has discussed some of the philosophical concepts of authenticity and contemporary epistemology, and these ideas have been utilized to develop a framework for interpreting the role played by ethical codes and IS methods in IS practice in modern organizations. IS methodologies seem to require authentic action in order to be successfully chosen-and-used for IS modeling. In choosing a methodology, relevance should determine the conduct of inquiry; in using methodologies, rigor will stem from the existence of adequate justification for the requirements elicited by the practitioners. Clearly work needs to be done in organizations to investigate how authenticity is actually mobilized (or not as the case may be) in organizations. Furthermore, the beneficial and/or detrimental affects that authentic activities have on the systems development process should also be investigated. Clearly, a (thinly-veiled) view that authenticity is inherently "a good thing" pervades this discussion, but it should be noted that authenticity cannot be something actually advocated without contradiction, as:

“[A]uthenticity does not denote 'objective qualities' such as those associated with the notions of sincerity and honesty, qualities one predicates of 'the person' in the same way one asserts, for instance, that 'the table is round or square'. The notion of authenticity, it seems, signifies something beyond the domain of objective language ... Its presence is defined in its absence, the passionate search for it, in inauthenticity and in various acts of 'bad faith' ...

Nietzsche, Kierkegaard and Camus. All agree in principle that any positive definition of authenticity would be selfnullifying." (Golomb, 1995, p. 7)

Although Nietzsche's version of authenticity has been basically characterized; other philosophers and authors of literature have made important contributions to the debate - including Heidegger. Further research would be needed to investigate these views, and these may be able to offer further insights in this area. However, it can be concluded that practitioners should be given (by project managers, etc.) considerable freedom to choose approaches to IS develop- ment that - from their perspective - suit the pertaining organizational circumstances. Furthermore, it may often be necessary for practitioners to move between (broadly-based) hard and soft, whole and part, and near-cookbook and nearad hoc approaches in many IS development projects. Iteration between phases and cross referencing should be encouraged, at least as far as the time-constraints of a particular IS development project allow. Finally, it should be noted that whilst this paper has gone some way to providing a coherent framework for interpreting practical action in IS development, Jayaratna's advice to the practitioner, "Not to hand over his or her thought processes to be directed by any external person, model, methodology or framework, including the one advocated in this [1994] book. Methodology users must become responsible for their thinking and actions." (Jayaratna, 1994, p. xiii) is pertinent here, as his comments apply to this paper also.

\section{References}

Boehm, B. (1976). Software Engineering. IEEE Computer, C-25(12).

Checkland, P., \& Holwell. S. (1998). Information, Systems and Information Systems - Making Sense of the Field. Chichester: Wiley.

Checkland, P., \& Scholes, J. (1990). Soft Systems Methodology in Action. Chichester: Wiley.

Cooper, D. E. (1983). Authenticity and Learning. London: Routledge and Kegan Paul.

Fidler, C., \& Rogerson, S. (1996). Strategic Management Support Systems. London: Pitman.

Fitzgerald, G., Phillipides, A., \& Probert, S. (1999). Maintenance, Enhancement and Flexibility in Information Systems Development. In: J. Zupancic, G. Wojtkowski, W. Wojtkowski \& S. Wrycza (Eds.), Evolutions and Challenges in Systems Development. New York: Kluwer Academic / Plenum.

Golomb, J. (1995). In Search of Authenticity. London: Routledge.

Haack, S. (1995). Evidence and Inquiry. Oxford: Blackwell.

Hirschheim R, Klein, H. K., \& Lyytinen, K. (1995) Information Systems Development and Data Modelling. Cambridge: Cambridge University Press.

Jayaratna, N. (1994). Understanding and Evaluating Methodologies. Maidenhead: McGraw-Hill.

Lewis, P. (1994). Information-Systems Development. London: Pitman.

Loucopoulos, P., \& Karakostas, V. (1995). System Requirements Engineering. Maidenhead: McGraw-Hill. 


\section{Modeling using IS Methodologies}

Mumford, E. (1995). Human Development, Ethical Behavior and Systems Design. In: N. Jayaratna, R. Miles, Y. Merali \& S. Probert (Eds.), Information Systems Development 1995. Swindon: BCS Publications.

Nietzsche, F. (1956). The Birth of Tragedy and the Genealogy of Morals. New York: Doubleday.

Nietzsche, F. (1974). The Gay Science. New York: Random House.

Thoreau, H. D. (1995). Civil Disobedience and Reading. London: Penguin.
Walsham, G. (1996). Ethical Theory, Codes of Ethics and IS Practice. Information Systems Journal, 6, 69-81.

Wastell, D. G. (1996). The Fetish of Technique: Methodology as a Social Defence. Information Systems Journal, 6, 25-40.

\section{Biography}

Stephen Probert teaches Information Systems at Cranfield University, Shrivenham. Previously, he taught at London University (Birkbeck College) and at the University of the West of England, Bristol. He has also acted as a Management Consultant to many UK organizations. 